\title{
Understanding and preventing hit-and-run driving: a crime script analysis ${ }^{1}$
}

\author{
Matt Hopkins and Sally Chivers
}

\begin{abstract}
Although a small body of research has explored drivers' decisions to leave the scene of a road traffic collision (hit-and-run) little research has explored how understanding the processes of hit-and-run collisions could inform prevention strategies. Drawing upon findings from a literature review and indepth interviews with 52 convicted hit-and-run drivers, a crime script approach is utilised as a heuristic device to explore the precursors, immediate aftermath and longer-term aftermath of hit-and-run events. This method allows for motivational factors to be identified. Then, utilising Clarke's techniques of situational crime prevention as a guiding framework, possibilities for the prevention of hit-and-run are presented.
\end{abstract}

\section{Introduction}

A hit-and-run collision is a road traffic crash where a driver of a striking vehicle flees the scene without aiding the victim or offering information (Roshandeh et al, 2016: 22). In the UK, the number of collisions involving a hit-and driver where an injury was sustained increased from 15,390 in 2013 to 17,122 in 2015. Over the same period of time the proportion of collisions involving a hit-and-driver (where an injury was sustained) also increased from 11.1\% in 2013 to 12.2\% in 2015 (DfT, 2016). Although official statistics record collisions where there is an injury or fatality, many more collisions also involve a hit-and-run driver where there is only damage to vehicles or road furniture. In addition, problems are also encountered when trying to identify the number of hit-and-run drivers traced and convicted per year. Hit-and-run is legally defined under the Road Traffic Act (1988) as failing to stop or report an accident involving a motor vehicle. ${ }^{2}$ However, while many hit-and-run drivers may eventually be charged for 'failure to stop' or 'failure to report', in more serious cases they could be charged across a range of offences such as dangerous/reckless/careless driving or manslaughter. As these offence categories also include many individuals who are not hit-and-run drivers, it can be difficult to accurately identify which cases involve a hit-and-run element.

Some previous research has identified contributory factors associated with hit-and-run collisions. These studies commonly develop logistic regression models that identify odds ratios of a range of factors being present or not at the scene of the crash (see for example, Zhang et al, 2014; Fujita et al, 2014; Tay et al, 2008). This approach limits our understanding of this complex crime type in two primary ways. First, the methodologies employed have focused on the relationship between contextual/contributory factors and hit-and-run collisions through the analysis of police records. This has neglected to engage directly with drivers and thus gain first-hand accounts about their decisions

\footnotetext{
${ }^{1}$ This research was funded by the Motor Insurers' Bureau.

${ }^{2}$ Section 170(4) of the Road Traffic Act 1988 requires a driver to stop if his/her motor vehicle has been involved in an accident which has caused injury to another person or animal, damage to another vehicle or damage to roadside property. There is then a duty to provide contact details (including name and address) and other appropriate information to any person who has reasonable grounds to request such information. In the event that the driver does not provide details at the scene, the accident must be reported at a police station or to a police constable as soon as reasonably practicable, or within 24 hours. Failure to do so is a criminal offence that carries a fine and potentially up to six months imprisonment. The offence also carries five to ten penalty points and/or a disqualification from driving.
} 
to leave the scene. Second, there has also been a failure to recognise that hit-and-run collisions are a process of events that can involve a range of actors and decision making points for those involved.

With these criticisms in mind, the aim of this paper is to better understand hit-and-run collisions and potential preventative strategies. This is achieved through an extensive literature review and analysis of 52 semi-structured interviews with convicted hit-and-run drivers that utilised a crime script approach as a heuristic device (see LeClerc \& Wortley, 2014). Below the analytical framework and methodology utilised in the study are outlined before we then outline the findings.

\section{Analytical framework and methodology}

An analytical framework based upon a crime scripts approached was developed. Crime scripts moves away from the notion that crimes are discrete events (Price et al, 2016) but rather conceptualises these as a sequence of events that involve a number of offender decision points. The approach has been applied to many crime types (such as shoplifting, money laundering and sexual offences - see Gilmour, 2014; LeClerc \& Wortley, 2014; Chiu \& Leclerc, 2016), where the necessary sequences for crime events and the dependencies necessary for events to occur have been identified. Although Price et al (2016) note that there is no agreed method or data source for producing a crime script, Socco and Kennedy (2008) usefully suggest that most crime events can be categorised into three distinct phases - precursors, transactions and aftermaths. Considering the potential complexity of a hit-andrun collision, a crime script approach seemed to have potential utility in developing an understanding of (a) the procedural or sequential requirements for collisions, (b) offender decision points and ultimately (c) preventative strategies. A hypothetical overview of a script for hit-and-run is presented in Figure one. This modifies Socco and Kennedy's (2008) model and considers a hit-and-run collision as three distinct phases:

1. Collision precursors/the collision itself: the background details to the collision, how the collision occurred and any pre-collision antecedents (such as no-insurance/invalid licence) that were present before the collision.

2. Immediate aftermath: what happened immediately after the collision and what motivated the driver to leave the scene.

3. Longer-term aftermath: what happened after the driver left the scene and how they were eventually captured.

Figure 1: The script of a hit-and-run event
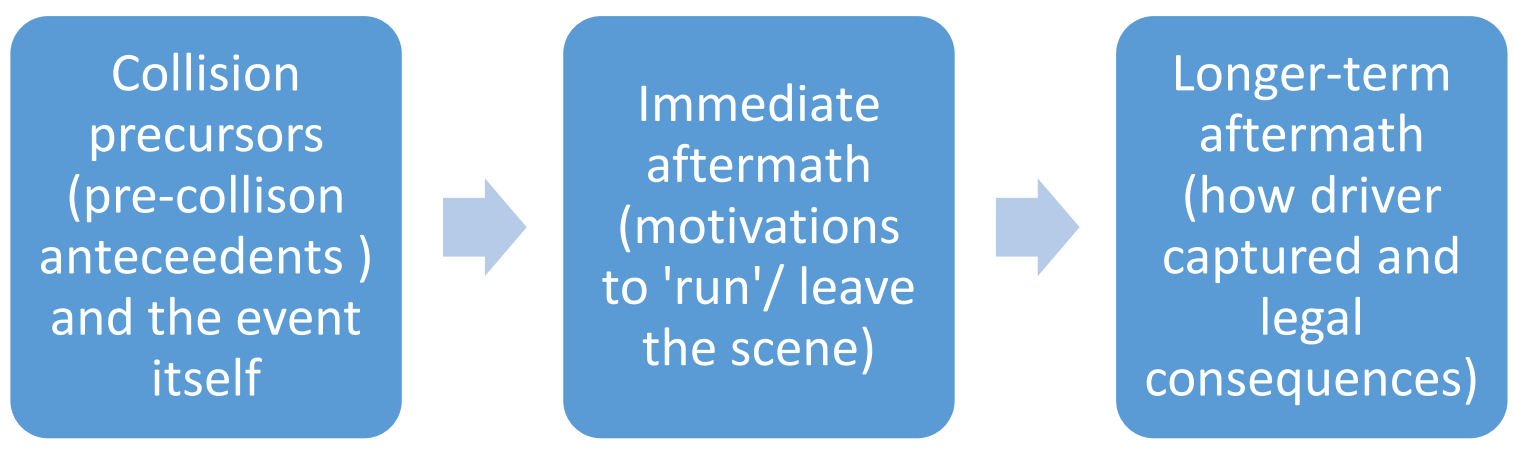

Of course, the major challenge faced by researchers trying to understand motivations for hit-and-run is in obtaining a sample of drivers involved in such collisions. By their nature hit-and-run cases involve 
drivers who have left the scene and are often not traced. In order to overcome this, a sample group was constructed of drivers who had left the scene of a collision, but were later traced and charged by the police. Drivers were initially contacted via the Driver and Vehicle Licensing Agency (DVLA) ${ }^{3}$, who hold records of all drivers convicted for offences of failure to stop after an accident (code AC10) or to report an accident within 24 hours (code AC20). A total of 19,071 drivers were identified on the DVLA database, who were initially contacted to participate in a national survey of hit-and-run drivers (see Hopkins \& Chivers, 2016). A total of 695 drivers responded to the survey. Of these, 357 agreed to be re-contracted for interview. All 357 were re-contacted to ensure (a) they were willing to participate in detailed interviews and (b) the collision they were involved in resulted in damage to either vehicles road future or injury to a pedestrian. A total of 52 respondents were then eventually interviewed. All of the interviews were tape recorded and transcribed verbatim.

Of the 52 drivers who were interviewed, $78 \%(n=41)$ were male and $19 \%(n=10)$ under the age of 34 . A total of $75 \%(n=39)$ also had previous motoring convictions (prior to the hit-and-run), with $46 \%$ $(n=24)$ being convicted of careless/ reckless/ dangerous driving in relation to the hit-and-run offence and $10 \%(n=5)$ of drink driving offences. The demographic characteristics of the interview group were broadly similar to the sample frame ( $81 \%$ of these were male and a quarter aged 34 or under). Of the sample frame, $75 \%$ also had a current endorsement on their record for motoring offences. A lower proportion of interviewees had a conviction on their record for careless/ reckless/ or dangerous driving (32\%) with a higher proportion for drink driving offences (20\%).

There were some limitations with the methodology which means that one has to interpret the findings with care. First, while the DVLA hold records for drivers convicted of AC10/20 offences, the complexity of hit-and-run cases means that many hit-and-run drivers can often be convicted for a variety of offences such as failure to stop/report, drink driving, dangerous driving and careless driving. The specific act of hit-and-run is recorded as an AC10/20 offence and this was the flag for searching the DVLA records. However, it may not be possible to identify all hit-and-run drivers from these offences as occasionally, courts will only report the highest sentence tariff offence to the DVLA. For example, if a driver is convicted of reckless driving as well as failure to stop/report, the court sentencing the driver may only notify DVLA of the most serious tariff offence - this potentially omits some hit-and-run drivers from the AC10/20 records. Second, care also has to be taken because of social desirability bias (see Davis \& Silver, 2003). Indeed, it was possible that interviewees might have given a version of events that distanced themselves from blame or wrongdoing. However, it should be noted that all drivers were already convicted and sentenced for the offence, so had little to gain (in a legal sense) from giving false accounts of events. Also, to mitigate for this, where possible, factual information was checked with DVLA records. However, there was no way to validating the detailed accounts that offenders gave of their decisions to leave the scene as no other records of this were available to the research team. Third, the sample population was not representative of the total hit-and-run population as (for example) no crashes involved a pedestrian fatality. However, as outlined above, a range of collision types were included which both involved damage-only and pedestrian injury. Fourth, when considered against the total number of hit-and-run collisions in the UK per year, a sample of 52 interviews is low. However, the purpose of the interviews was not to obtain a statistically representative sample, but to capture in-depth accounts of decision making to complement existing large quantitative studies. Finally, the charge could also be made that the sample is biased as the

\footnotetext{
${ }^{3}$ The DVLA maintain the registration and licensing of drivers in Great Britain and the registration and licensing of vehicles in the UK.
} 
decision making processes of those who are convicted could be different from those who are not traced. This might be true, however, it was not possible to recruit untraced drivers to the research.

Using the crime script framework described above, the following sections draw upon the previous literature and the interviews with hit-and-run drivers to identify precursors to collisions, driver motivations and how drivers were eventually traced. We then explore the possibilities for prevention.

\section{Precursors to collisions: identifying pre-collision antecedents}

A body of research has explored the reasons for hit-and-run in countries such as China (Zhang et al, 2014), Japan (Fujita et al (2014), Singapore (Tay et al, 2008) and Ghana (Aidoo et al, 2013). These studies have commonly been based conducted analysis of large accident datasets to identify contributory factors in relation to crash types, human and vehicle characteristics, road factors, environment and distraction factors. A brief synopsis is presented below:

- Crash types: Zhang et al (2014) found that in Ghana and Tay et al $(2008,2009)$ found (in Singapore and the USA respectively) that collisions involving pedestrians were more likely to involve a hit-and-run driver. However, in their analysis of drivers in Illnois (USA), Zhou et al (2016) found that drivers are more likely to stay at the scene when somebody is injured and leave after damage-only collisions.

- Human factors: Most studies suggest that offenders are commonly male (Zhang et al, 2014; Tay et al, 2010), have previous convictions for motoring related offences (MacLeod et al, 2012; Solnick \& Henenway, 1995) and often do not have a valid licence (MacLeod et al, 2012; Zhang et al, 2016). Zhang et al (2014) found that in Ghana younger drivers (aged 25-44) and less experienced drivers were more likely to flee a collision, though others studies have suggested middle aged drivers (45-69) are more likely to flee (Tay et al, 2008; 2010). Drivers are less likely to leave the scene if a victim is either very young or old (MacLeod et al, 2012) and drivers most likely to be identified when victims are young (MacLeod et al, 2012). Alcohol consumption is a common contributory factor in both collisions involving pedestrians (MacLeod et al, 2012) and damage-only cases (Jiang et al, 2016).

- Vehicle characteristics: Zhang et al (2014) identify that drivers of newer cars are less likely to flee from crashes; drivers involved in collisions with buses are also less likely to hit-and-run (as there are likely to be witnesses).

- Road factors: Tay et al (2009) observe a greater likelihood of hit-and-run on flat, level roads or those with lower speed limits (45 mph or less). Zhang et al (2014) observed high rates of hit-and-run on elevated roads, those with merging lanes and at tunnels.

- Environment: a number of studies suggest hit-and-run collisions tend to occur at weekends (MacLeod et al, 2012; Solnick \& Henenway, 1995; Tay et al, 2010) and when visibility/ light conditions are poor (Tay et al, 2008, 2009; MacLeod et al, 2012). However, there is contradictory evidence about the effect of adverse weather conditions on the likelihood of hit-and-run (Jiang et al, 2016). Some studies suggest drivers are more likely to run in poor weather (Tay et al, 2008) others such as Zhang et al (2014) observed no effect.

- Driver distraction: a growing body of research has also started to consider how driver distraction factors - such as operating an electronic communication device (a cell phone, DVD player or navigation system); distraction from outside the vehicle (such as dangerous overtaking) distraction from inside (such as chatting with passengers) - can influence driver decisions to leave the scene. Roshandeh et al, (2016) identify that the presence of a distraction factor most significantly increases the odds of a driver leaving the scene when they hit a parked vehicle. 
While these previous studies clearly identify contributory factors, they are limited as they have not engaged with driver accounts of their decision making processes. Although some research (see for example Dalby \& Nesca, 2008) have utilised small samples of illustrative case studies, no known research has conducted detailed interviews with drivers to identify motivational factors. It is to this we now turn.

\section{Immediate and longer-term aftermath: Establishing drivers' motivations for hit-and-run}

Below, evidence is considered from 52 interviews with convicted hit-and-run drivers. All interviews were conducted between February and April 2016 and were related to collisions that took place in the UK. Table two outlines the extent of damage in the collision and the penalty types drivers received. This shows that:

1. In 13 collisions there was extensive damage to any vehicle; in such cases at least one vehicle was either written off or there were questions over whether the vehicle could be driven away from the collision.

2. In 15 collisions there was some damage to a vehicle or road furniture; in such cases there were clearly visible dents to body work.

3. In 19 cases there was minor damage to a vehicle (such as paintwork scratches) or to road furniture.

4. In 12 collisions a pedestrian or cyclist claimed to be injured in some way. ${ }^{4}$

Table 1: Penalty type received for leaving the scene by type of damage (number of cases by type of damage)

\begin{tabular}{|l|c|c|c|c|}
\hline $\begin{array}{l}\text { Damage sustained in } \\
\text { collision }\end{array}$ & $\begin{array}{c}\text { Points on } \\
\text { licence }\end{array}$ & Fine & $\begin{array}{c}\text { Driving ban/ } \\
\text { disqualification }\end{array}$ & $\begin{array}{c}\text { Prison/ } \\
\text { suspended } \\
\text { sentence }\end{array}$ \\
\hline Extensive damage $(\mathbf{n}=13)$ & 4 & 8 & 7 & 3 \\
\hline Some damage (n=15) & 10 & 14 & 2 & 2 \\
\hline Minor (n=19) & 16 & 16 & 1 & 1 \\
\hline $\begin{array}{l}\text { Any collisions involving } \\
\text { pedestrians ( } \mathbf{n}=12)\end{array}$ & 8 & 7 & 4 & 1 \\
\hline
\end{tabular}

Base: in-depth interviews with drivers, $n=52$.

Note: The number of penalty types do not add up to the number of collisions as many drivers will receive more than one type of penalty per collision.

Most of the interviewees were able to describe (to varying degrees of clarity) what happened in the immediate and longer-term aftermath. What was apparent in the interviews (and possibly most important for crime prevention purposes) was that drivers were able to outline clear reasons as to why they left the scene of the collision. In nearly all cases these could be linked to either antecedent factors that were present before the collision or situational factors that arose as a result of the collision. In all, six motivational typologies of hit-and-run driver were observed (these are summarised in Table two).

\footnotetext{
${ }^{4}$ This totals 64 collisions as there is double counting in relation to the collisions where pedestrians were involved.
} 
Previous research has commonly suggested that drivers make rational decisions to 'run' (see Tay et al, 2008; Fujita, 2014). In ten cases in this study drivers were classified as 'rational escapists' in that they were aware of the likely consequences of reporting the collision and viewed leaving the scene as a risk worth taking. Such drivers were commonly driving illegally (they did not have a valid licence or insurance). Indeed, a respondent who was driving without valid insurance ${ }^{5}$ said:

I think in the back of my mind my biggest worry was, it's going to make it even harder to get insurance. I knew it was wrong at the time, I just drove off. (Interview 44)

Others were worried about the potential punishment they might face. For example, one driver was concerned about the possibility of a prison sentence as he was disqualified at the time of the offence. His car slid into another on ice which caused the airbags to go off. As he was disqualified he ran away from the scene:

'I had a chance of going back to prison if I was there, whereas if I ran off I thought it would have been harder for them to trace that I was driving.' (Interview 37)

Table 2: Hit-and-run: driver typologies and motivations ${ }^{6}$

\begin{tabular}{|l|l|}
\hline $\begin{array}{l}\text { Offender } \\
\text { typologies }\end{array}$ & Description of typologies/key motivations \\
\hline $\begin{array}{l}\text { The rational } \\
\text { escapists ( } n=10)\end{array}$ & $\begin{array}{l}\text { Drivers who make a rational decision to leave the scene (by considering the } \\
\text { consequences of reporting). This group may make a rational decision to leave to either } \\
\text { (1) hide criminality or (2) avoid the possibility of increased insurance premiums. The key } \\
\text { reason for leaving the scene is present before the collision. }\end{array}$ \\
\hline $\begin{array}{l}\text { The panickers } \\
\text { (n=7) }\end{array}$ & $\begin{array}{l}\text { The initial response of this group is to 'panic' at the scene (regardless of blame or extent } \\
\text { of damage/injury), which is followed by an overwhelming desire to leave the scene. }\end{array}$ \\
\hline $\begin{array}{l}\text { Drinkers, the } \\
\text { impaired or 'non } \\
\text { compos mentis' } \\
\text { (n=7) }\end{array}$ & $\begin{array}{l}\text { Drivers who are drunk or drugged at the time of the collision. This may be the cause of } \\
\text { the collision and can impairs judgement over whether to stay at the scene or not. Similar } \\
\text { to the rational escapists, the key reason for leaving the scene is present before the } \\
\text { collision. }\end{array}$ \\
\hline $\begin{array}{l}\text { The intimidated } \\
\text { (n=4) }\end{array}$ & $\begin{array}{l}\text { Drivers who face aggression from other drivers or pedestrians and as a consequence } \\
\text { leave the scene. }\end{array}$ \\
\hline $\begin{array}{l}\text { The uncertain } \\
\text { departers ( } n=16)\end{array}$ & $\begin{array}{l}\text { Drivers who are unsure whether the collision should be reported or not, based on their } \\
\text { judgement that the collision is too trivial. }\end{array}$ \\
\hline $\begin{array}{l}\text { The oblivious } \\
(n-8)\end{array}$ & Drivers who are unsure that a collision has occurred. \\
\hline
\end{tabular}

The rational escapists contrasted with a group of drivers who described a sense of panic $(n=7)$ as their main motivation. Previous research has suggested panic or 'flight responses' as a reason for hit-andrun (Dalby \& Nesca, 2008). Interestingly, panic responses were observed in collisions that included

\footnotetext{
${ }^{5}$ Indeed, the initial survey of 695 drivers (See Hopkins \& Chivers, 2016) highlighted that around 1 in 20 fled the scene because they were not insured and did not want to face the consequences.

${ }^{6}$ What is apparent in all of the observed cases is that the collisions were accidental. This potentially excludes cases where there was a deliberate attempt to damage a vehicle or pedestrian.
} 
both minor and serious damage and were often related to the 'shock' of being in a collision and the driver inability to cope with the situation. Indeed, two drivers described how they were unable to cope with the stress of being in a collision and others described how the presence of other factors (such as the police) enhanced their sense of panic:

'Anyway [I] panicked ... started driving off ... seen a police car come in behind me and I decided I wasn't going to stop and I escaped from the police. I then dumped my car around a side road ... they did a trace on my name and they tracked me down.' (Interview 13)

In seven cases driver judgement was either impaired in some way or they were unable to make a rational choice at the time of the collision due to alcohol consumption or being mentally unwell. Indeed, the association between drink/drug taking and traffic offences is well recognised (see Solnick \& Hemenway, 1994; Beirness et al, 2008; Bjorgo, 2016) and in five cases alcohol was the primary reason for the collision they were involved in. While four drivers could be described as acting rationally in that they were aware that (as a result of drinking) being caught at the scene would mean prosecution for drink driving, often the fact they had been drinking made them take risks that were irrational. For example, after one collision where serious damage was caused to two cars, a driver left the scene of the collision on foot. He said his car was 'my pride and joy but was smashed to pieces', but knowing he was over the 'drink drive' limit said 'I done a runner' (Interview 43). Worryingly, another drink driver said being over the limit made him determined to escape from the scene:

I just knew what sort of trouble I'd be in. I just knew that I'd be over the limit, I shouldn't have drove. I shouldn't have been on the road at the time, it was just a young stupid mistake. I knew what the consequences were so I thought at least if I can get away for a little while. (Interview 1)

In the following case, a driver was so drunk she had no knowledge of the collision and thus made no decision to leave the scene at all:

..... it wasn't that I was deliberately driving away from the accident and hoping I'd get away with, I was so drunk I had no idea. (Interview 8).

Importantly, three groups emerged that have not been widely identified in previous research - the intimidated, uncertain departers and the oblivious. The intimidated $(n=4)$ described being victims of aggression from other drivers or bystanders as the major reason for leaving the scene. By contrast the uncertain departers $(n=16)$ claimed to have been involved in a trivial collision that they did not think required reporting (such as hitting road furniture) or they were unaware of the legal requirement to report. Finally, in six cases drivers were oblivious to the fact they had been involved in a collision at all. In two cases the 'oblivious' were elderly drivers, who were unaware of their surroundings. In other cases these tended to be HGV or van drivers who did not realise they had hit a cyclist or other object.

Of course, a key problem for law enforcement (and insurance) in relation to hit-and-run is in tracing drivers. Thus, what happens in the longer-term aftermath is therefore also important, though little known research has explored this. Solnick \& Hemenway (1995) observed (in relation to fatal collisions involving pedestrians) that when victims are under 15 years of age and when collisions occurred in daylight hours the chances of drivers being identified more than doubles. Our initial survey of 695 hitand-run drivers (see Hopkins \& Chivers, 2016) identified that in the majority of cases (54\%) drivers were traced as a pedestrian or another driver was proactive and noted down the registration number of the vehicle. In one in ten cases, drivers were identified via CCTV/ANPR and in just over one in ten 
cases, drivers reported themselves to the police. Interestingly, drivers were more likely to later turn themselves in if a pedestrian had been involved in the collision. Indeed, Solnick \& Hemenway (1995) observed that not only are drivers less likely to initially leave the scene if they hit a child or elderly person, but they are also more likely to later turn themselves in.

\section{The prevention of hit-and-run}

To date, there has been little systematic attempt to develop strategies to prevent hit-and-run based upon understanding precursors, situational factors and the likelihood of driver capture. However, this is not to say that researchers have not given any attention to the subject. For example, in their study of over 47,000 collisions in the USA (of which 8,000 involved a hit-and-run driver) Grembek \& Griswold (2012) explored whether strict judicial sentences acted as a deterrent. They observed that a deterrence approach via legal sanctions appeared to have little effect on the likelihood of drivers leaving the scene as many are unaware of the likely sentence they will receive, and often they are confident they will avoid capture (thus knowledge of punishment is unknown and certainty of punishment is negligible). Moreover, Fujita et al (2014) argued that in Japan, harsher legal punishment appears to have lowered the number of pedestrian collisions, but actually increased the proportion involving a hit-and-run driver. It is also evident that a number of situationally focused preventative strategies have been developed that do not specifically focus on hit-and-run, but target commonly observed contributory factors (such as drink driving and uninsured driving) and also aim to increase surveillance of 'illegal' driving on the roads (through road cameras and the use of dashboard cameras).

Below we employ the crime script model and also borrow from Clarke's techniques of situational crime prevention (see Clarke, 1997) to develop a framework to identify a number of preventative approaches that might be tailored to hit-and-run. The analysis in the previous section illustrates that hit-and-run is unlike many crime types that situational approaches have previously been applied to. Situational crime prevention commonly starts from the premise that offenders often make rational choice decisions to offend when opportunities for crime present themselves (Newman \& Freilich, 2012). However, this normally applies in contexts where offenders are motivated and tempted by sufficient rewards to make the effort to commit crime worthwhile. In relation to hit-and-run, drivers rarely plan to be involved in a collision that leads to a situation where they face a decision about whether to stay or leave the scene. Thus they do not make the same type of rational decision as, for example, a burglar determining which targets to select. Drivers tend to find themselves in a situation where they have been in a collision and are often motivated to leave in order to avoid the consequences of reporting (Tay et al 2008). However, it is evident that decisions to leave the scene can be affected by antecedent factors that are present before the collision and situational factors that arise as a result of the collision. Using Clarke's framework we examine how preventative approaches might help to shape these decisions to 'run' through: (1) increasing the effort, reducing the benefits and the excuses for motivated offenders to drive a vehicle illegally; and (2) increasing the risks of drivers being observed at the collision scene, reducing provocations and excuses to leave the scene. We also consider which strategies might increase the likelihood of drivers being captured after the collision or turning themselves in.

The identified preventative possibilities are presented in Table three. Column one presents those aimed at tackling precursors/antecedents of hit-and-run collisions. Indeed, much previous work has been conducted to tackle the direct antecedents of collisions and to reduce the likelihood of illegal driving, such as driving over the drink or drugs limit (see Bjorgo, 2016). In relation to hit-and-run drivers such approaches might be best targeted towards potential rational escapists or the impaired/non compos mentis and include: 
- Increasing the effort for potential offenders to drive illegally: using Alcolocks ${ }^{7}$ to prevent vehicle use after drinking or clamping vehicles that have been identified as uninsured.

- Remove rewards/benefits of illegal driving: encouraging drivers who have been drinking to use public transport/ provide regular and cheap night time public transport. Use of telematics or 'black box' insurance ${ }^{8}$ to encourage safe driving.

- Remove excuses for illegal driving: training for 'high risk' categories of drivers about the dangers of illegal driving and what to do in the event of a collision. This might include reviewing and expanding upon current questions in the theory driving test, ${ }^{9}$ getting driving schools to include information as part of their driver training and promoting awareness of hitand-run on speed awareness courses. Indeed, training for at-risk groups and alerting driver's conscience might help improve driver culture (especially amongst the young and most at-risk). Campaigns to raise awareness of the dangers and illegality of using distractions (such as mobile phones) when driving could also help tackle antecedents related to hit-and-run.

Column two details interventions aimed at tackling situational factors that might reduce the likelihood of drivers leaving the scene. These include:

- Increasing the risks of leaving the scene: Fujita et al (2014) suggest that the most important measure for 'preventing a driver fleeing the scene to make the driver perceive they might be witnessed'. Indeed, the utilisation of CCTV in public/private spaces to capture collisions/drivers leaving the scene, encourage bystanders to be active in logging vehicle details and promote the use of dashboard cameras and personal cameras to increase surveillance would increase the risk for drivers. Fujita et al (2014) also suggest that placing 'ecall systems' in vehicles that automatically dial the emergency services after a collision would increase the risk of leaving the scene.

- Remove provocations to leave scene: these might primarily be aimed towards drivers who feel intimidated at the scene through the use of 'safe spaces' (such as petrol stations) where collisions could be reported free from other aggressive drivers or bystanders.

- Remove excuses for non-reporting: clarify rules on the reporting of collisions to drivers through the distribution of 'collision' information cards (which could be issued through insurance companies or DVLA). ${ }^{10}$ There could also be engagement with employers to encourage and more actively promote the employer's roles and responsibilities with regard to work-related driving. Employers not only have a corporate social responsibility but a legal responsibility in managing how their staff use the road for work, providing training and instruction where necessary. If drivers do leave the scene they might be able to use alternative means of reporting ${ }^{11}$ such as a 'Mobile Collision Reporting App' which would allow reporting via a mobile device. Driver conscience could also be alerted through educating drivers about the financial and moral consequences of hit-and-run.

\footnotetext{
${ }^{7}$ Alcolocks are breathalyser immobilisers that prevent an individual from driving while over the legally allowed alcohol limit.

8 Telematics monitor how well a person drives. Insurance premiums are then based on how safe and conscientious a driver is.

${ }^{9}$ There is a question about exchanging details in a collision in the current theory test, though additional questions might be added.

${ }^{10}$ Some insurance companies do currently have such literature, but not in a standardised format.

${ }^{11}$ Currently legislation stipulates that if someone fails to stop at the scene and exchange details they must report in person at a police station or to a police officer within 24 hours.
} 
Table 3: Possibilities for prevention and driver capture using techniques of situational crime prevention

\begin{tabular}{|c|c|c|}
\hline $\begin{array}{l}\text { Targeting precursors/ } \\
\text { antecedents of hit-and-run }\end{array}$ & $\begin{array}{l}\text { Targeting situational factors/ } \\
\text { reduce likelihood of driver } \\
\text { leaving the scene }\end{array}$ & $\begin{array}{l}\text { Driver capture: increase } \\
\text { likelihood of driver capture } \\
\text { or 'turning in' }\end{array}$ \\
\hline $\begin{array}{l}\text { Increase effort to drive } \\
\text { illegally: } \\
\text {-Use of Alcolock ignition } \\
\text { systems to deny vehicle use. } \\
\text {-Clamp uninsured vehicles to } \\
\text { deny vehicle use. }\end{array}$ & $\begin{array}{l}\text { Increase risks of leaving scene: } \\
\text {-Utilisation of CCTV in public and } \\
\text { private spaces. } \\
\text {-Encourage bystanders to take } \\
\text { vehicle details. } \\
\text {-Use of dashboard cameras, } \\
\text { cameras for cyclists and drivers. } \\
\text {-Automatic 'e-call' systems in } \\
\text { vehicles }\end{array}$ & $\begin{array}{l}\text { Increase risks of capture: } \\
\text {-Incentives for garages that } \\
\text { 'turn in' owners of cars } \\
\text { involved in hit-and-run. } \\
\text {-Extended formal } \\
\text { surveillance including use of } \\
\text { ANPR systems to locate } \\
\text { vehicles. } \\
\text { - Alert driver's conscience } \\
\text { through media publicity in } \\
\text { relation to most serious } \\
\text { collisions involving serious } \\
\text { injury. }\end{array}$ \\
\hline $\begin{array}{l}\text { Remove rewards/benefits of } \\
\text { illegal driving: } \\
\text {-Provision of night time } \\
\text { transport to reduce } \\
\text { temptations to drink or drug } \\
\text { drive. } \\
\text {-Use of telematics or 'black } \\
\text { box' insurance. }\end{array}$ & $\begin{array}{l}\text { Remove provocations to leave } \\
\text { the scene: } \\
\text {-Promote safe places to report if } \\
\text { drivers feel intimidated. }\end{array}$ & \\
\hline $\begin{array}{l}\text { Remove excuses for illegal } \\
\text { driving: } \\
\text {-Training for 'at risk' groups of } \\
\text { drivers at post-conviction } \\
\text { training events. } \\
\text {-Breathalysers in pubs/server } \\
\text { intervention. } \\
\text {-Insurance reminders. } \\
\text {-Campaigns to tackle } \\
\text { distractions such as mobile } \\
\text { phone use. }\end{array}$ & $\begin{array}{l}\text { Remove excuses for non- } \\
\text { reporting: } \\
\text {-Clarify rules on driver's legal } \\
\text { responsibilities via } \\
\text { education/distribution of } \\
\text { 'collision' cards to drivers via } \\
\text { insurance. } \\
\text {-Promote employer responsibility } \\
\text { and engagement. } \\
\text {-Develop alternative means of } \\
\text { reporting such as use of mobile } \\
\text { applications to report. } \\
\text { - Alert driver's conscience to } \\
\text { financial and moral } \\
\text { consequences of hit-and-run. }\end{array}$ & \\
\hline
\end{tabular}

Column three presents interventions that might increase the likelihood of driver capture or encourage drivers to turn themselves in after a hit-and-run. These could be tailored towards all groups of hitand-run drivers and include: 
- Providing incentives to report suspected hit-and-run drivers: encourage agencies and bodies that potentially have contact with hit-and-run offenders to report, for example, breakdown organisations and repair and body shops. In some countries a police report number is required in order to get a car repaired.

- Extending formal surveillance: through the use of Automatic Number Plate Recognition (ANPR) systems to locate vehicles.

- Alert driver's conscience: using the media to publicise the serious potential physical and financial impacts of hit-and-run collisions on victims.

The possibilities outlined above are not meant to be exhaustive, though they do illustrate how preventative interventions could be targeted to different stages of the hit-and-run process. Of course, it is evident that some groups, such as the uncertain departers, might be more easily targeted than offenders where serious damage is caused, where illegal goods/drugs are being transported or where there was intent to injure a pedestrian.

\section{Conclusion}

This paper has developed a more holistic analysis of hit-and-run collisions than previously attempted. While previous research has identified contributory contexts of hit-and-run, a major limitation is (a) the lack of engagement with drivers convicted for hit-and-run offences and (b) consideration of hitand-run as a process of events. By using a crime script approach, it is observed that hit-and-run can be a complex process of events that include precursors to the collision, the immediate aftermath of the collision and the longer-term aftermath. Indeed, drivers themselves describe a range of motivational factors for leaving the scene and a number of hit-and-run typologies can be identified. These motivational factors are largely a product of 'pre-collision antecedents' (such as not having insurance) or they are situationally generated after the collision. It is evident that despite the complexity of hit-and-run, theoretical explanations for drivers' motivations and preventative strategies could be further developed. This research represents a first tentative step towards developing both a more holistic understanding of these motivations and potential preventative strategies.

\section{References}

Beirness, D. J., Clayton, A. \& Vanlaar, W. (2008) An Investigation of the Usefulness, the Acceptability and Impact on Lifestyle of Alcohol Ignition Interlocks in Drink-driving Offenders Usability of Alcolocks (Road Safety Research Report), Road Safety Research Report 88: London: Department for Transport.

Bjorgo, T. (2016) Preventing Crime: A Holistic Approach. Basingstoke: Palgrave MacMillan.

Chiu, Y. \& Leclerc, B. (2016) 'An Examination of Sexual Offences Against Women by Acquaintances: The Utility of a Script Framework for Prevention Purposes'. In B, Leclerc. \& E. Savona. (eds.) Crime Prevention in the $21^{\text {st }}$ Century. Switzerland: Springer.

Clarke, R. (1997) Situational Crime Prevention: Successful Case Studies ( $2^{\text {nd }}$ edition) New York: Harrow \& Heston.

Dalby, T. \& Nesca, M. (2008) 'The psychology of hit-and-run', Law Enforcement Executive Forum 8(5): 51-56.

Davis, D. \& Silver, B. (2003) 'Stereotype Threat and Race of Interviewer Effects in a Survey of Political Knowledge'. American Journal of Political Science, Vol 47, No 1: pp. 33-45. 
Department for Transport (DfT) (2016) Accidents Involving a Hit-and-Run Vehicle, Great Britain, 20052015. Data supplied by Department for Transport, London.

Fujita, G., Okamura, K., Kihira, M. \& Kosuge, R. (2014) 'Factors contributing to driver choice after hitting a pedestrian in Japan'. Accident Analysis and Prevention, 72 pp. 277-286.

Jiang, C., Linjun, L., Chen, S., \& John Lu, J. (2016) 'Hit-and-run crashes in urban river-crossing road tunnels'. Accident Analysis and Prevention, 95 pp. 373-380.

Gilmour, N. (2014) 'Understanding money laundering - a crime script approach'. The European Review of Organised Crime, 1(2): 35-56.

Grembek, O. \& Griswold, J. (2012) On the Legal Deterrence of Pedestrian Hit-and-Run Collisions. Working Paper. University of California, Berkley: Safe Transportation Research and Education Center. https://safetrec.berkeley.edu/publications/legal-deterrence-pedestrian-hit-and-run-collisions

Hopkins, M. \& Chivers, S. (2016) 'A national survey: Why do drivers fail to stop and report an accident?' https://www.mib.org.uk/media-centre/news/2016/april/new-research-shows-why-drivers-hit-andrun/

LeClerc, B. \& Wortley, R. (eds) (2014) Cognition and crime: offender decision making and script analyses. Oxon: Routledge.

Macleod, K., Griswold, J., Arnold, L. \& Ragland, D. (2012) 'Factors associated with hit-and-run pedestrian fatalities and driver identification'. Accident Analysis and Prevention, 45: 336-372.

Newman, G. \& Freilich, J. (2012) 'Extending the reach of situational crime prevention'. In N, Tilley. \& G. Farrell. (eds.) The Reasoning Criminologist: Essays in Honour of Ronald V. Clarke. London: Routledge. pp. 212-225.

Price, V., Sidebottom, A. \& Tilley, N. (2016) 'Understanding and Prevention Lead Theft in Churches: A Script Analysis'. In L, Grove. and S, Thomas. (eds.) Heritage Crime: Progress, Prospects and Prevention. Basingstoke: Palgrave MacMillan Publishers. pp. 128-148.

Roshandeh, A., Zhou, B. \& Behnood, A. (2016) 'Comparison of contributing factors in hit-and-run crashes with distracted and non-distracted drivers'. Transportation Research Part F (38): 32-28.

Socco, V. and Kennedy, L. (2008) The Criminal Event: An Introduction to Criminology in Canada. Fourth Edition. Toronto: Thomson Nelson.

Solnick, S. \& Hemenway, D. (1994) 'Hit the bottle and run: the role of alcohol in hit- and-run pedestrian fatalities'. Journal of Studies on Alcohol, 55 (6): 679-684.

Solnick, S. \& Hemenway, D. (1995) 'The hit-and-run in fatal pedestrian accidents: victims, circumstances and drivers'. Accident Analysis Prevention, 27 (5): 643- 649.

Tay, R., Rifaat, S. \& Chin, H. (2008) 'A logistic model of the effects of roadway, environmental, vehicle, accident and driver characteristics on hit-and-run crashes'. Accident Analysis and Prevention, 40 (4): 1330-1336.

Tay, R., Barua, U. \& Kattan, L. (2009) 'Factors contributing to hit-and-run in fatal crashes'. Accident Analysis and Prevention, 41: 227-233. 
Tay, R., Kattan, L. \& Sun, H. (2010) 'A Logistic Model of Hit-and-Run Crashes in Calgary'. Canadian Journal of Transportation, Vol 4: 1-10.

Zhang, G., Li, G., Cai, T., Bishai, D., Wu, C. \& Chan, Z. (2014) 'Factors contributing to hit-and-run crashes in China'. Transportation Research Part F (23): 113-124.

Zhou, B., Roshandeh, A., Zhang, S. \& Ma, Z. (2016) 'Analysis of Factors Contributing to Hitand-run Crashes Involved with Improper Driving Behaviours'. Procedia Engineering, 137, pp. 554-562. 